\title{
Effect of perinatal risk factors on coagulation system in premature infants
}

\author{
Karima Abd-elhalim Mahfouz, Hatem Refaat Hablas, Mahmoud Abdellatif Hashish, \\ Mohammed Hosney Youssef Mohammed Sokkar*
}

Departments of Clinical Pathology, Faculty of Medicine, Al-Azhr University

*Corresponding author: Mohammed Hosney Youssef Mohammed Sokkar, E-Mail: sokkar2016@gmail.com, Mobile: 01004554436

\begin{abstract}
Background: neonates have different blood clotting and fibrinolytic activities from the adults. Compared with full-term infants, premature infants are more prone to bleeding diathesis after birth, such as intracranial hemorrhage and pulmonary hemorrhage. The defective coagulation factors in premature infants contribute to predisposition of bleeding in premature infants.

Objective: it was to assess the hemostatic profile by screening tests in preterm infants with perinatal risk factors.

Patients and Methods: the study was conducted on 90 subjects, 30 preterm with risk factors, 20 preterm without risk factors, 30 full term and 10 adults. All of them were subjected to full clinical history, examination and routine investigation including $\mathrm{CBC}$, prothrombin time, activated partial thromboplastin time, thrombin time and fibrinogen concentration.

Results: the results of this study revealed a prolongation in the PT, APTT and TT together with a lower fibrinogen concentration in the group of preterm without risk factors in comparison with the group of full term and adult and revealed that there is more prolongation in the PT, APTT and TT together with more decrease in fibrinogen concentration in the group of preterm with risk factors in comparison with the group of preterm without risk factors, full term and adult but there is no significant difference between full term and adult as regard PT, APTT, TT and fibrinogen concentration.
\end{abstract}

Conclusion: preterm infants without perinatal risk factors show a lower hemostatic profile when compared with healthy full term and adult. Preterm infants with perinatal risk factors show more decrease in hemostatic profile when compared with healthy full term and adult. Perinatal risk factors (preeclampsia, diabetes and urinary tract infection) seem to interfere with coagulation protein synthesis.

Keywords: Perinatal risk factors, preterm infants, fibrinogen concentration, thrombin time, coagulation system

\section{INTRODUCTION}

Hemostasis is a process which keeps blood flowing freely within blood vessel ${ }^{(\mathbf{1})}$. Hemostasis is the first stage of wound healing. This involves three major component:1) vasoconstriction, 2) temporary blockage of a break by a platelet plug, and 3) blood coagulation (blood changing from a liquid to a gel), and formation of a fibrin clot. Hemostasis involves as well arrest on going thrombosis and repair ${ }^{(2)}$.

Coagulation is the process by which blood changes from liquid to gel, forming a blood clot. It begins almost after an injury to the blood vessel has damaged the endothelium lining the vessel. Leaking the blood through the endothelium initiates two processes: (1) changes in platelets, (2) exposure of subendothelial tissue factor to plasma factor VII and factor XII which ultimately leads to fibrin formation ${ }^{(3)}$.

There are the contact activation pathway (also known as the intrinsic pathway), and the tissue factor pathway (also known as the extrinsic pathway) which both lead to the same fundamental reactions that produce fibrin ${ }^{(3)}$.

The coagulation factors are generally serine proteases (enzymes), which act by itself or in combination with other factors cleaving downstream proteins. The coagulation factors circulate as inactive zymogens ${ }^{(4)}$.

Developmental haemostasis represents the maturation of the haemostatic system from birth to adulthood. There are differences in the concentration, structure and activity of many proteins involved in blood clotting ${ }^{(5)}$. These changes are necessary for physiological development and providing appropriate diagnosis and treatment of bleeding and clotting disorders (e.g. thrombosis) ${ }^{(6)}$.

Fibrinogen (factor I) is a glycoprotein that is converted enzymatically by thrombin to fibrin and subsequently to a fibrin-based blood clot during tissue and vascular injury ${ }^{(7)}$. 
Fibrinogen functions primarily to occlude blood vessels injury and thereby stop excessive bleeding. Fibrinogen's product, fibrin, after sealing the injured vascular area, entours the active thrombin in its meshwork isolating it away from the field to stop propagation of the thrombus preventing vascular occlusion, binds and reduces the activity of thrombin. Fibrin also mediates blood platelet and endothelial cell spreading, tissue fibroblast proliferation, and thereby functions to promote tissue revascularization, wound healing and tissue repair ${ }^{(7)}$.

\section{Aim of the work}

The aim of the study is to assess the hemostatic profile in preterm infants compared with normal full term once by screening tests. The influence of perinatal risk factors on the coagulation system in preterm infants should be taken on consider.

\section{SUBJECTS AND METHODS Subjects:}

This study was conducted in collaboration between the Clinical Pathology and Pediatric departments at Al Hussien University Hospital, Faculty of Medicine, AlAzhar University.

This study was approved by the Ethics Board of AlAzhar University.

All patients were collected from Pediatric department at Al Hussien University Hospital over a period from 8th May 2018 to 5th August 2018, with appropriate consent to participate in this study after explanation to the parents of participants how much it is helpful in diagnosis and treatment and also explaining to them that it is just a blood sample collection. The present subjects were divided into 2 groups: (patients group) and (control group). The patients group was subdivided into 2 subgroups according to the presence of risk factors (preeclampsia, diabetes and urinary tract infection) as follows:

- Subgroup B: comprised 30 preterm babies with risk factors.

- Subgroup C: comprised 20 preterm babies without risk factors.

Control group (A): 30 apparently healthy full term babies and 10 healthy adult.

\section{SAMPLES AND METHODS}

Full history and clinical examination

Venous blood $(2.3 \mathrm{ml})$ were withdrawn from all participants of the study and divided into two portions: the first portion $(0.5 \mathrm{ml})$ was taken in EDTA tube for CBC which was done using fully automated cell counter(Sysmex $\mathrm{Kx}-21)$. The second portion $(1.8 \mathrm{ml})$ was taken in Na-citrate $3.2 \%$ tube for coagulation tests (PT, APTT, TT and fibrinogen concentration). Test sample should be prepared from citrated blood as we mix carefully 1 part sodium citrate solution with 9 parts venous blood avoiding the formation of foam. Immediately we centrifuge for 10 minutes at approximately $3000 \mathrm{rpm}$ then we remove the supernatant plasma and keep it at room temperature. The clotting time in seconds for PT, APTT and TT will be recorded by semi-automated (Diagnostica stago).

\section{Statistical analysis}

Data were analyzed using Statistical Program for Social Science (SPSS) version 15.0. Qualitative data were expressed as frequency and percentage.The following test was done:Chi-square test: was used when comparing between non-parametric data.

\section{RESULTS}

As regard fibrinogen concentration, thrombin, PT and APTT, there was statistically highly significant difference (P-value < 0.0001) between preterm with risk factors and preterm without risk factors as regard fibrinogen, thrombin and PT. There is no statistical significant difference ( $\mathrm{p}$-value $>0.05$ ) between preterm with risk factors and preterm without risk factors as regard APTT, table (1).

Results show highly statistical significant difference ( $p$-value < 0.001) between preterm with risk factors and full term as regard fibrinogen, thrombin, PT and APTT, table (2).

Results show highly statistical significant difference ( $\mathrm{p}$-value < 0.001) between preterm with risk factors and adult as regard fibrinogen, thrombin, PT and APTT, table (3).

Results show no statistical significant difference (pvalue > 0.05) between full term and adult as regard fibrinogen, thrombin, PT and APTT, table (4). 
Table (1): Comparison between preterm with risk factors and preterm without risk factors as regard fibrinogen, thrombin, PT and APTT.

\begin{tabular}{|c|c|c|c|c|}
\hline \multicolumn{2}{|c|}{ Variables } & $\begin{array}{c}\text { Preterm with risk } \\
\text { factors } \\
(\mathrm{N}=30)\end{array}$ & $\begin{array}{c}\text { Preterm without risk } \\
\text { factors } \\
(\mathrm{N}=20)\end{array}$ & P-value \\
\hline \multirow{2}{*}{ Fibrinogen } & Mean & 100.9 & 145.01 & \multirow{2}{*}{$<0.001$ : } \\
\hline & \pm SD & 23.8 & 8.3 & \\
\hline \multirow{2}{*}{ Thrombin time } & Mean & 40.3 & 30.9 & \multirow{2}{*}{$<0.001$ : } \\
\hline & \pm SD & 11.3 & 3.4 & \\
\hline \multirow{2}{*}{ PT } & Mean & 28.3 & 23.1 & \multirow{2}{*}{$<0.001$} \\
\hline & \pm SD & 4.8 & 4.1 & \\
\hline \multirow{2}{*}{ APTT } & Mean & 87.5 & 86.3 & \multirow{2}{*}{0.6} \\
\hline & \pm SD & 7.3 & 8.5 & \\
\hline
\end{tabular}

Table (2): Comparison between preterm with risk factors and full term as regard fibrinogen, thrombin, PT and APTT.

\begin{tabular}{|c|c|c|c|c|}
\hline \multicolumn{2}{|l|}{ Variables } & $\begin{array}{c}\text { Preterm with risk } \\
\text { factors } \\
(\mathrm{N}=30)\end{array}$ & $\begin{array}{l}\text { Full term } \\
(\mathrm{N}=30)\end{array}$ & P-value \\
\hline \multirow{2}{*}{ Fibrinogen } & Mean & 100.9 & 260.7 & \multirow{2}{*}{$<0.001 *$} \\
\hline & \pm SD & 23.8 & 50.7 & \\
\hline \multirow{2}{*}{ Thrombin time } & Mean & 40.3 & 17.01 & \multirow{2}{*}{$<0.001 *$} \\
\hline & \pm SD & 11.3 & 1.6 & \\
\hline \multirow{2}{*}{$\mathrm{PT}$} & Mean & 28.3 & 13.4 & \multirow{2}{*}{$<0.001 *$} \\
\hline & $\pm \mathrm{SD}$ & 4.8 & 0.7 & \\
\hline \multirow{2}{*}{ APTT } & Mean & 87.5 & 35.1 & \multirow{2}{*}{$<0.001 *$} \\
\hline & $\pm \mathrm{SD}$ & 7.3 & 2.5 & \\
\hline
\end{tabular}

Table (3): Comparison between preterm with risk factors and adult as regard fibrinogen, thrombin, PT and APTT.

\begin{tabular}{|c|c|c|c|c|}
\hline \multicolumn{2}{|l|}{ Variables } & $\begin{array}{l}\text { Preterm with risk } \\
\text { factors } \\
(\mathrm{N}=30)\end{array}$ & $\begin{array}{c}\text { Adult } \\
(\mathrm{N}=10)\end{array}$ & P-value \\
\hline \multirow{2}{*}{ Fibrinogen } & Mean & 100.9 & 281.1 & \multirow{2}{*}{$<0.001 *$} \\
\hline & $\pm \mathrm{SD}$ & 23.8 & 60.7 & \\
\hline \multirow{2}{*}{ Thrombin time } & Mean & 40.3 & 17.9 & \multirow{2}{*}{$<0.001 *$} \\
\hline & $\pm \mathrm{SD}$ & 11.3 & 1.5 & \\
\hline \multirow{2}{*}{ PT } & Mean & 28.3 & 13.5 & \multirow{2}{*}{$<0.001 *$} \\
\hline & \pm SD & 4.8 & 0.8 & \\
\hline \multirow{2}{*}{ APTT } & Mean & 87.5 & 33.6 & \multirow{2}{*}{$<0.001 *$} \\
\hline & \pm SD & 7.3 & 4.1 & \\
\hline
\end{tabular}


Table (4): Comparison between full term and adult as regard fibrinogen, thrombin, PT and APTT.

\begin{tabular}{|c|c|c|c|c|}
\hline \multicolumn{2}{|l|}{ Variables } & $\begin{array}{r}\text { Full term } \\
(\mathrm{N}=30)\end{array}$ & $\begin{array}{c}\text { Adult } \\
(\mathrm{N}=10)\end{array}$ & P-value \\
\hline \multirow{2}{*}{ Fibrinogen } & 260.7 & 281.1 & 260.7 & \multirow{2}{*}{0.3} \\
\hline & 50.7 & 60.7 & 50.7 & \\
\hline \multirow{2}{*}{ Thrombin time } & 17.01 & 17.9 & 17.01 & \multirow{2}{*}{0.1} \\
\hline & 1.6 & 1.5 & 1.6 & \\
\hline \multirow{2}{*}{ PT } & 13.4 & 13.5 & 13.4 & \multirow{2}{*}{0.8} \\
\hline & 0.7 & 0.8 & 0.7 & \\
\hline \multirow{2}{*}{ APTT } & 35.1 & 33.6 & 35.1 & \multirow{2}{*}{0.2} \\
\hline & 2.5 & 4.1 & 2.5 & \\
\hline
\end{tabular}

\section{DISCUSSION}

Neonates have different hemostatic, blood clotting and fibrinolytic activites from the adults. As well there are noticeable bleeding differences between premature and full-term infants. Compared with full-term infants, premature infants are more prone to bleeding diathesis after birth, such as intracranial hemorrhage, pulmonary hemorrhage, hemorrhage of digestive tract ${ }^{(8)}$.

Neonates have different fibrinogen form when compared with adult form as fetal form has increased sialic acid content compared to adult fibrinogen. The functional implications of these differences are reflected in prolonged thrombin clotting times in newborns as well as differences in polymerization of fibrin from 'fetal' fibrinogen ${ }^{(9)}$.

This study was designed to develop appropriate reference ranges for prothrombin time (PT), activated partial thromboplastin time (APTT), thrombin time and fibrinogen concentration and to assess the hemostatic profile by screening tests in preterm infants with risk factors compared with preterm infants without risk factors. Normal full term and adult were used as control group.

In this study, prothrombin time in the group of preterm with risk factors was (mean $\pm \mathrm{SD}=28.3 \pm 4.8$ sec.) while in the group of preterm without risk factors was (mean $\pm \mathrm{SD}=23.1 \pm 4.1 \mathrm{sec}$.) so there is highly statistical significant difference ( $p$-value $<0.001)$ between preterm with risk factors and preterm without risk factors as regard prothrombin time more prolonged in the preterm with risk factors. Neary et al. ${ }^{(10)}$ who carried out a study to measure standard plasma coagulation tests in premature infants compared with term infants is similar to the current study results of PT.
The study enrolled 116 preterm babies who have perinatal risk factors compared with healthy full term babies (control group). Prothrombin time was 17.5 (12.7- 26.6) second $(\mathrm{p}<0.001)$ so there is highly statistical significant difference between preterm without risk factors and full term as regard prothrombin time more prolonged in the preterm.

Activated partial thromboplastin time in the group of preterm without risk factors was (mean $\pm \mathrm{SD}=$ $86.3 \pm 8.5 \mathrm{sec}$.) while in the group of full term was (mean $\pm \mathrm{SD}=35.1 \pm 2.5 \mathrm{sec}$.) so there is highly statistical significant difference ( $\mathrm{p}$-value $<0.001$ ) between preterm without risk factors and full term as regard activated partial thromboplastin time more prolonged in the preterm. Neary et al. (10) results are similar to the current study results of APTT. APTT was 78.7 (48.7-134.3) second $(\mathrm{p}<0.001)$ so there is highly statistical significant difference between preterm without risk factors and full term as regard activated partial thromboplastin time more prolonged in the preterm. Lippi et al. ${ }^{(11)}$ made a study for routine coagulation tests in newborn infant and adult. The study of Lippi et al. ${ }^{(11)}$ showed that the mean APTT value was higher than the upper limit of the adult reference range so APTT more prolonged in newborn.

Thrombin time in the group of preterm without risk factors was (mean $\pm \mathrm{SD}=30.9 \pm 3.4 \mathrm{sec}$.) while in the group of full term was (mean $\pm \mathrm{SD}=17.01 \pm 1.6 \mathrm{sec}$.) so there is highly statistical significant difference ( $p$-value $<0.001$ ) between preterm without risk factors and full term as regard thrombin time more prolonged in the preterm.

The concentration of fibrinogen in the group of preterm with risk factors was (mean $\pm \mathrm{SD}=100.9 \pm 23.8$ 
$\mathrm{mg} / \mathrm{dl}$ ) while in the group of preterm without risk factors was (mean $\pm \mathrm{SD}=145.01 \pm 8.3 \mathrm{mg} / \mathrm{dl}$ ) so there is highly statistical significant difference (p-value < 0.001 ) between preterm with risk factors and preterm without risk factors as regard fibrinogen concentration more decreased in the preterm with risk factors. The concentration of fibrinogen in the group of preterm with risk factors was (mean $\pm \mathrm{SD}=100.9 \pm 23.8 \mathrm{mg} / \mathrm{dl}$ ) while in the group of full term was (mean $\pm \mathrm{SD}=$ $260.7 \pm 50.7 \mathrm{mg} / \mathrm{dl}) \quad$ so there is highly statistical significant difference (p-value $<0.001$ ) between preterm with risk factors and full term as regard fibrinogen concentration more decreased in the preterm. Poralla et al. ${ }^{(12)}$ who carried out a study to evaluate the influence of preterm delivery and perinatal risk factors on fibrinogen concentration in preterm infants. The study enrolled 132 preterm babies who have perinatal risk factors compared with healthy full term babies (control group). The concentration of fibrinogen was $($ mean \pm SD: $112.66 \pm 15.83 \mathrm{mg} / \mathrm{dl}$ vs. $280 \pm 24.27$ $\mathrm{pg} / \mathrm{mL}, \mathrm{p}<0.001)$ so there is highly statistical significant difference between preterm babies who have perinatal risk factors and healthy full term babies as regard fibrinogen concentration more decreased in preterm . Lippi et al. ${ }^{(11)}$ made a study for routine coagulation tests in newborn and adult. The study of Lippi et al. ${ }^{(11)}$ show that the mean fibrinogen value was already within the adult reference range in newborns at birth so there is no statistical significant difference between full term and adult as regard fibrinogen concentration.

The results of this study indicated that the concentration of fibrinogen in the group of preterm with risk factors was markedly decreased in comparison with the group of full term and adult and indicated that thrombin time, Prothrombin time and APTT in the group of preterm with risk factors were markedly prolonged in comparison with the group of full term and adult.

From this study we found that preterm infants show a lower hemostatic profile (prolonged prothrombin time, activated partial thromboplastin time, thrombin time and decreased fibrinogen concentration) when compared with full term infants and adult. Perinatal risk factors (preeclampsia, diabetes and urinary tract infection) further has its impact on hemostasis in addition to interference with coagulation protein synthesis, complication as DIC could aggravate the hemostatic defect unfortunately we did not measure $\mathrm{D}$ dimer. This is due to liver immaturity and decrease protein synthesis including coagulation factors quantitative and qualitative ${ }^{(\mathbf{1 1})}$.
The results of the present investigation demonstrate that the actual adult reference ranges for coagulation screening tests, PT and APTT, cannot be applied to preterm babies.

\section{CONCLUSION}

Preterm infants without perinatal risk factors show a lower hemostatic profle profile when compared with preterm infants with perinatal risk factors, healthy full term and adult. Preterm infants with perinatal risk factors show a lower hemostatic profile when compared with healthy full term and adult. Perinatal risk factors such as preeclampsia, diabetes and UTI seem to interfere with coagulation protein synthesis. Early management of preeclampsia, UTI and control of gestational diabetes may decrease the probability of preterm delivery and so may prevent the adverse effects of these risk factors on the coagulation system of infants.

\section{RECOMMENDATION}

Follow up studies should be considered in order to determine the effect of perinatal risk factors on coagulation system in preterm infants. By this study, fibrinogen concentration is a predictive factor for assessment of the effect of risk factors on coagulation system in preterm infants. Further studies should be done for other coagulation factors.

\section{REFERENCES}

1. Periayah MH, Halim AS, Mat Saad AZ (2017): Mechanism Action of Platelets and Crucial Blood Coagulation Pathways in Hemostasis. International Journal of Hematology-Oncology and Stem Cell Research, 11(4): 319-327.

2. Moake JL (2013): Overview of hemostasis. The Merck manual professional edition, publisher.

3. Pallister CJ and Watson MS (2010): Hematology. Scion Publishing.

4. Hall JE, Guyton AC (2011): Guyton and Hall Textbook of Medical Physiology, 12th ed. Philadelphia, PA: Saunders Elsevier.

5. Monagle $P$, Barnes $C$, Ignjatovic $V$, Furmedge J, Newall F, Chan A, De Rosa L, Hamilton S, Ragg P, Robinson S, Auldist A, Crock C, Roy N, Rowlands S (2006): Developmental Haemostasis: Impact for clinical haemostasis laboratories. Thrombosis and Haemostasis, 95: 362-372.

6. Ignjatovic V, Mertyn E, Monagle P (2011): The coagulation system in children: developmental and pathophysiological considerations. Seminars in Thrombosis and Haemostasis, 37(7):723-9. 
7. Moerloose P, Casini A, Neerman-Arbez M (2013): Congenital fibrinogen disorders: an update. doi:10.1055/s-0033-1349222.

8. Gruel Y (2010): Specificities of neonatal hemostasis and implications in pathologic situations. Arch Pediatr, 17 (3):S93-100.

9. Ignjatovic V, Mertyn E, Monagle P (2011): The coagulation system in children: developmental and pathophysiological considerations. https://wwww.unboundmedicine.com/.../The_coagulation _system_in_children:_devel
10. Neary E, McCallion N, Kevane B, Cotter M, Egan K, Regan I, Kirkham C, Mooney C, CoulterSmith S, Ní Áinle F (2015): Coagulation indices in very preterm infants from cord blood and postnatal samples. J Thromb Haemost, 13 (11):2021-30.

11. Lippi G, Salvagno G, Rugolotto S et al. (2007): Routine coagulation tests in newborn and young infants. Journal of thrombosis and thrombolysis, (24): 153-5.

12. Poralla C, Traut C, Hertfelder HJ, Oldenburg J, Bartmann P, Heep A (2012): The coagulation system of extremely preterm infants: influence of perinatal risk factors on coagulation. J Perinatol, 32(11):869-73. 